\title{
Suppurative mastoid lymphadenitis mimicking mastoiditis: a case report
}

\author{
Oleksii O. Tymofieiev ${ }^{1}$, Natalia O. Ushko ${ }^{1}$, levgen I. Fesenko ${ }^{3, *}$, \\ Olexander O. Tymofieiev ${ }^{4}$, Maria O. Yarifa ${ }^{2}$, Olha S. Cherniak ${ }^{5}$ \\ ${ }^{\prime}$ Department of Maxillofacial Surgery, Shupyk National Healthcare University of Ukraine, \\ ${ }^{2}$ Department of Oral and Maxillofacial Surgery, Private Higher Educational Establishment "Kyiv Medical University", \\ ${ }^{3}$ Center of Maxillofacial Surgery, Kyiv Regional Clinical Hospital, \\ ${ }^{4}$ Department of Dentistry, Shupyk National Healthcare University of Ukraine, \\ ${ }^{5}$ Department of Ultrasound, Regional Diagnostic Center, Kyiv Regional Clinical Hospital, Kyiv, Ukraine
}

Abstract (J Korean Assoc Oral Maxillofac Surg 2021;47:398-402)

Mastoid lymph node inflammation is a rare entity. Pathological conditions in the vicinity of the mastoid processes can be challenging for maxillofacial head-neck surgeons to address. We report a case of suppurative mastoid lymphadenitis in an 18-year-old Caucasian male. To our knowledge, there are no publications that highlight the clinical, ultrasonographic, intra-, and postoperative data for any pathologic process that presented as mastoiditis.

Key words: Mastoid lymph nodes, Suppurative mastoid lymphadenitis, Abscess, Mastoiditis, Ultrasound [paper submitted 2020. 2. 4 / revised 2020. 5. 2 / accepted 2020. 5. 5]

\section{Introduction}

Mastoid lymph nodes (MLNs), or retroauricular lymph nodes $^{1}$, are a small group of usually two nodes that belong to the superficial lymph node group of the head ${ }^{2}$. They are located in both retroauricular areas, in the mastoid region and are more numerous in children ${ }^{3}$. Lengelé et al. ${ }^{4}$ reported that, "draining the temporal region of the hairy scalp, the posterior surface of the auricle and the posterior wall of the external acoustic meatus, MLNs have efferent vessels which traverse the upper insertions of the sternocleidomastoid muscle to join the superior deep lateral cervical lymph nodes".

Currently, only a limited number of publications has high-

\section{Ievgen I. Fesenko}

Center of Maxillofacial Surgery, Kyiv Regional Clinical Hospital, Kyiv Ukraine

*Current affiliation: Department of Oral and Maxillofacial Surgery, Private Higher Educational Establishment "Kyiv Medical University", 7 Antona Tsedika Street, Kyiv 02000, Ukraine

TEL: +38-063-293-18-13

E-mail: i.i.fesenko@dtjournal.org

ORCID: https://orcid.org/0000-0002-8901-1632

(c) This is an open-access article distributed under the terms of the Creative Commons Attribution Non-Commercial License (http://creativecommons.org/ licenses/by-nc/4.0/), which permits unrestricted non-commercial use, distribution, and reproduction in any medium, provided the original work is properly cited.

Copyright (C) 2021 The Korean Association of Oral and Maxillofacial Surgeons. lighted the pathological conditions that can involve the MLNs as a result of different etiologies: cat scratch disease lymphadenopathy $^{5}$, post-microneedling mastoid lymphadenopathy ${ }^{1}$, and a pathologic process in a mastoid area can often mimic mastoiditis ${ }^{6-8}$.

Normal, metastatic ${ }^{9}$, reactive ${ }^{10}$, and suppurated lymph nodes show different ultrasound patterns, which help medical workers to establish correct diagnosis and management approach and to prevent complications. Suppurative lymphadenopathy in different parts of the human body demonstrates very specific ultrasound features, including anechoic regions, septations, peripheral vascularity, and posterior acoustic enhancement artifact ${ }^{11}$ that are related to necrosis within lymph nodes, also known as intranodal abscess formation or purulent fusion of the lymph nodes ${ }^{12}$.

To our knowledge, there are no publications that have highlighted the clinical, ultrasonographic, intra-, and postoperative data for suppurative mastoid lymphadenitis that presented as mastoiditis. The purpose of the report is to present an extremely rare case of the pathologic process that can be referred to both oral-maxillofacial and head neck surgeons for treatment. 


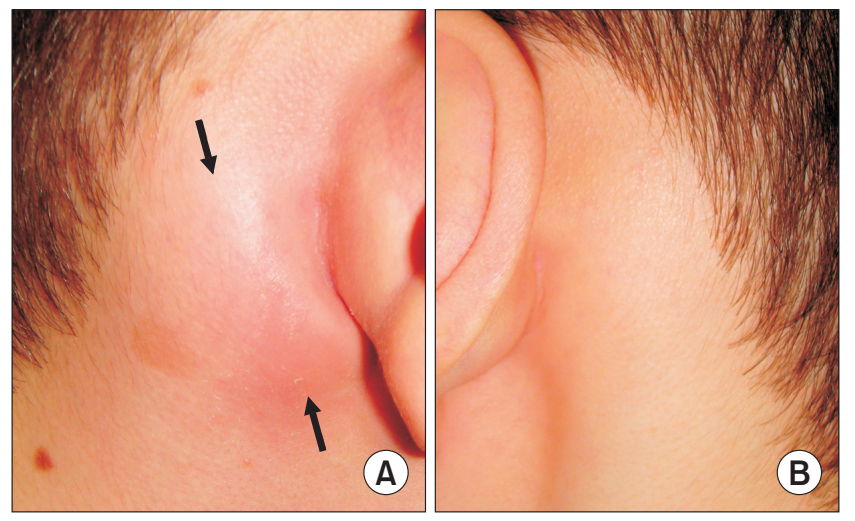

Fig. 1. Right lateral view (A) shows a right suppurative mastoid lymphadenitis (arrows) and left view (B) demonstrates the nonsymptomatic side.

Oleksii O. Tymofieiev et al: Suppurative mastoid lymphadenitis mimicking mastoiditis: a case report. J Korean Assoc Oral Maxillofac Surg 2021

\section{Case Report}

The patient was an 18-year-old Caucasian male who was referred to the Center of Maxillofacial Surgery from the Kyiv region with painful right retroauricular swelling and fever. The patient reported that the symptoms had started about one week prior; after experiencing hypothermia, swelling of the soft tissue of the right neck was noted. A physician diagnosed acute cervical lymphadenitis and prescribed treatment (oral Augmentin) after which the edema of the neck resolved, although edema in the right mastoid persisted and became painful and red.

Examination revealed painful swelling of the soft tissue above the right mastoid process (Fig. 1) with significant erythema. Simultaneously, the patient noted no ear pain or pressure, and purulent discharge from the ear and hearing loss were absent. Emergency gray scale (B-mode) and color Doppler ultrasound (US) (HD11 XE; Philips, Amsterdam, The Netherlands) showed soft tissue edema above the mastoid process, a $1.19 \times 0.61-\mathrm{cm}$ reactive upper posterior MLN with marked hilar vascularity (Fig. 2) and no ultrasound signs of suppuration. Color Doppler US in a slightly anterior and lower transducer position compared to the previous scan demonstrated a limited collection of pus (Fig. 3) at a place where the lower anterior MLN was presumably located. US of the right parotid area and neck also showed an increase in the size of one intraparotid and multiple cervical reactive lymph nodes with hilar vascularity. A diagnosis of right cervical and suppurative right mastoid lymphadenitis was made after the US investigation. The patient and his parents declined a surgical treatment approach; however, he was referred to our Center
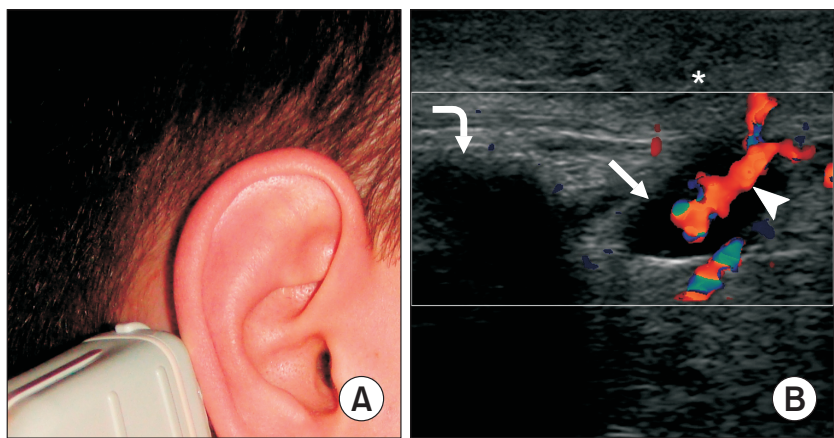

Fig. 2. The left image (A) shows the patient and symptomatic area from a longitudinal transducer position. Color Doppler sonogram (B) demonstrates soft tissue edema (asterisk) above the mastoid process (curved arrow), a 1.19×0.61-cm reactive upper posterior mastoid lymph node (arrowhead) with a marked hilar vascularity (arrow) and no ultrasound signs of suppuration. The oval shape of the node corresponds to reactive lymphadenitis. Depth of ultrasonography is $3.0 \mathrm{~cm}$.

Oleksii O. Tymofieiev et al: Suppurative mastoid lymphadenitis mimicking mastoiditis: a case report. J Korean Assoc Oral Maxillofac Surg 2021
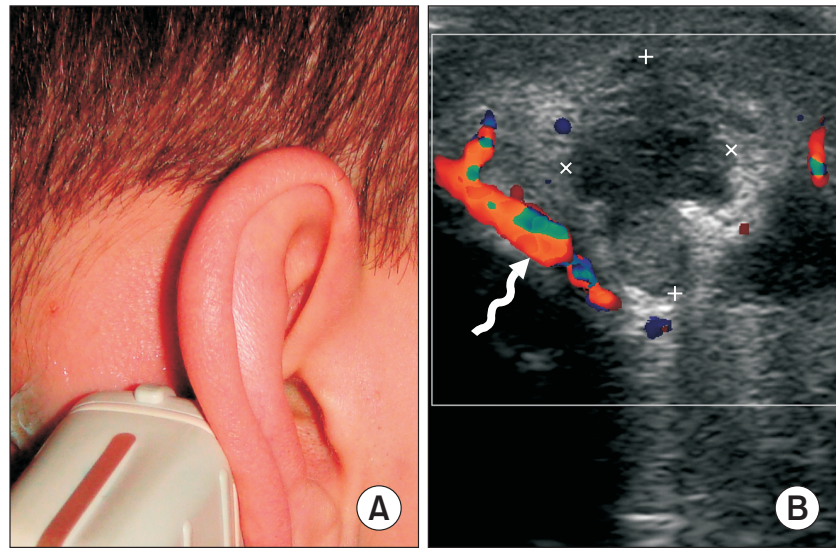

Fig. 3. Image (A) shows the symptomatic area in a longitudinal transducer position. Color Doppler ultrasound image (B) demonstrates a limited collection of pus (the borders are indicated by "+" and " $x$ " calipers) at a place where the lower anterior mastoid lymph node was presumably located. Posterior auricular vessel is indicated by a waved arrow. Depth of ultrasonography is $3.0 \mathrm{~cm}$. Oleksii O. Tymofieiev et al: Suppurative mastoid lymphadenitis mimicking mastoiditis: a case report. J Korean Assoc Oral Maxillofac Surg 2021

again after only two days. At his second visit, increase of mastoid swelling, local skin erythema (Fig. 4. A), and fever were noted. The local pain became unbearable for the patient. Fluctuation upon additional examination informed the diagnosis, which was changed to "abscess of the right mastoid area". Abscess lancing (under local anesthesia $[2.0 \mathrm{~mL}$ of $4 \%$ Ultracain D-S forte; Aventis Pharma Deutschland, Frankfurt, Germany]) revealed $\sim 4.0 \mathrm{~mL}$ of pus (Fig. 4. B), and curettage (Fig. 4. C) showed only purulent content with no residual parts of the suppurated MLNs. The patient received intrave- 

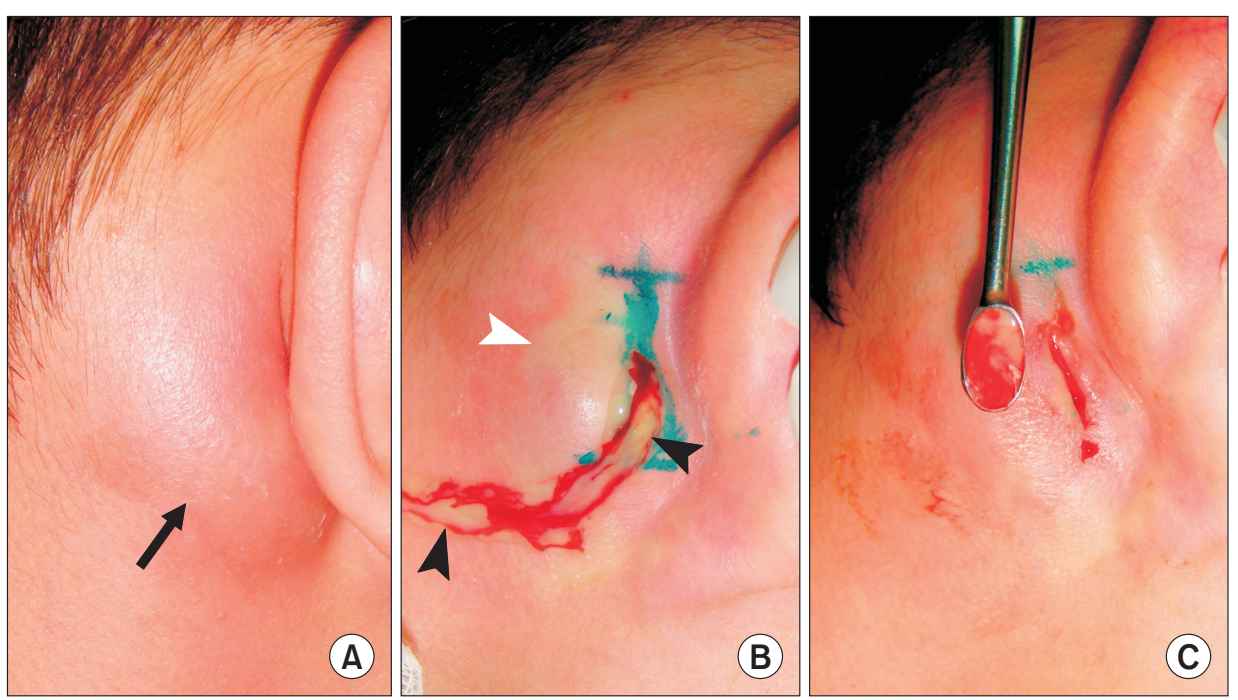

Fig. 4. Preoperatively (A) the lesion was noted with painful swelling, erythema, and fluctuation in the right mastoid area (arrow). A mastoid area abscess lancing (B) revealed $\sim 4.0 \mathrm{~mL}$ of pus (black arrowheads) (white arrowhead indicates on skin ischemia as a result of local anesthesia) and curettage (C) showed only purulent content with no residual parts of the suppurated mastoid lymph nodes.

Oleksii O. Tymofieiev et al: Suppurative mastoid lymphadenitis mimicking mastoiditis: a case report. $J$ Korean Assoc Oral Maxillofac Surg 2021
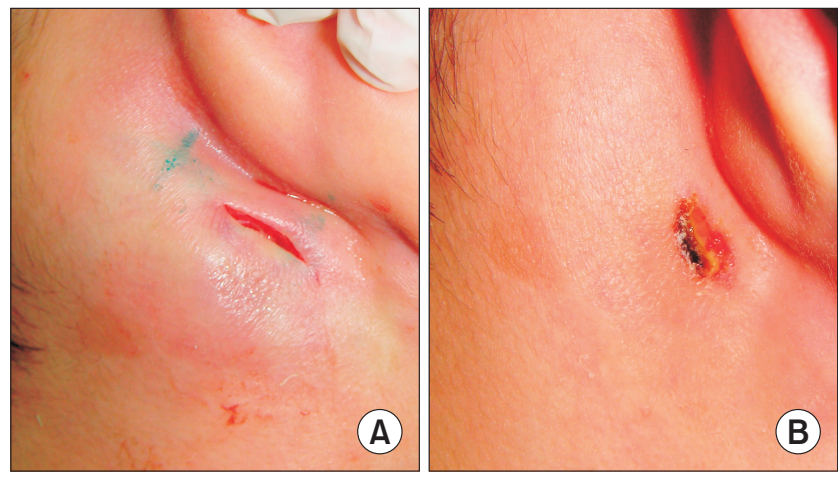

Fig. 5. Wound view immediately (A) after abscess lancing and on the fourth day (B) of healing by secondary intention.

Oleksii O. Tymofieiev et al: Suppurative mastoid lymphadenitis mimicking mastoiditis: a case report. J Korean Assoc Oral Maxillofac Surg 2021

nous ceftriaxone $1.0 \mathrm{~g}$ two times daily and wound bandages with Oflocain-Darnitsa ointment (components: lidocaine hydrochloride and ofloxacin; Darnitsa, Kyiv, Ukraine), which have hyperosmolar properties. The postoperative period was smooth, and the wound healed by secondary intention.(Fig. 5)

\section{Discussion}

Infection of the MLNs or "lymph glands" occurs rarely, and cases that have reported an abscess following suppurative mastoid lymphadenitis are limited. To understand the pathologic condition, it is important to know the anatomy of MLNs and the ultrasound appearance of lymph nodes (normal, reactive, and lymph node metastases), which can easily differentiate mastoid lymphadenitis from mastoiditis, other types of abscesses, or acute otitis media.

Despite the data from Ahuja and Evans ${ }^{13}$ that MLNs in adults are usually involuted, our case clearly demonstrated the presence of two mastoid nodes, in a reactive and suppurated state, in an 18-year-old patient. Because parotid and submandibular nodes can be round in shape, this should not be used as the sole criterion for lymph node metastases ${ }^{14}$. Nodal size alone cannot be used as a criterion to differentiate between reactive and metastatic lymph nodes ${ }^{15}$. Calcification within normal and reactive nodes lymph nodes is uncommon $^{15}$. Typically, on color and power Doppler, normal nodes show hilar vascularity or appear avascular, and reactive nodes predominantly show hilar vascularity ${ }^{16,17}$.

Hernandez et al. ${ }^{18}$ emphasized that acute lymphadenitis develops over days, whereas subacute or chronic lymphadenitis develops over weeks to months. McMillan et al. ${ }^{19}$ reported that statistically one-third of infected nodes suppurate and become fluctuant. Further, for cases of suppurative lymphadenitis, a meticulous curettage approach is mandatory because it helps to remove residual parts of partially suppurated nodes. Abscess/phlegmon formation following a suppurative lymphadenitis in some East-European countries is referred to as "adenoabscess" and "adenophlegmon" "20 "Abscess-forming lymphadenopathy" can be considered a synonym of "abscess following a lymphadenitis" and "adenoabscess".

Dudkiewicz et al..$^{21}$ described that acute mastoiditis becomes clinically significant when the infection spreads and induces periostitis, thus visually mimicking suppurative mastoid lymphadenitis. The term "Luc's abscess" is applied only to a subperiosteal temporal abscess, or a limited collection of pus, as a complication of acute otitis media ${ }^{22}$. Another term, "Bezold's abscess," refers to an abscess that arises within the substance of the sternomastoid or digastric muscle following 
spread of pus through the tip of the mastoid process ${ }^{23,24}$.

Selecting the best diagnostic method is important for differential diagnosis between mastoid lymphadenopathy and mastoiditis; this process should be guided by the anamnesis morbi, a clinical picture of the pathologic process, and by the understanding that ultrasonography should have diagnostic priority over methods that use ionizing radiation, such as computed tomography (CT) or X-ray. Pattanayak et al. ${ }^{25}$ showed that both B-mode and color Doppler US can be used to detect reactive lymph nodes with almost perfect accuracy. According to their data, B-mode features for reactive lymph nodes had a sensitivity of $88 \%$, a specificity of $97.3 \%$, and color Doppler US had a sensitivity of $92 \%$ and a specificity of $97.3 \%{ }^{25}$. CT is strongly recommended in cases when a soft tissue edema in the retroauricular area combines with otorrhea (ear discharge), otalgia and hearing loss in the affected side. Vazquez et al. ${ }^{26}$ reported that worldwide sensitivity of CT for assessing acute mastoiditis is between $87 \%-100 \%$.

Mastoid suppurative lymphadenitis, similar to any purulent condition, should be treated quickly, with the intent to avoid secondary osteomyelitis of the mastoid process of the temporal bone (osteomyelitis of the mastoid) or mastoiditis. Osteomyelitis of the mastoid is very rare but commonly occurs secondary to otitis externa or suppurative otitis media. In some cases, acute mastoiditis can result in a retroauricular subcutaneous abscess, which presents with the same lateral characteristics as this case report, at the mastoid area with swelling and erythema.

In conclusion, suppurative lymphadenitis of the mastoid nodes is a rare entity. When encountered, pus draining with curettage of the parts of the lymph nodes which have not degraded should be considered as the first treatment modality. For this case of abscess that followed lymphadenitis, lancing resulted in a quick recovery.

\section{ORCID}

Oleksii O. Tymofieiev, https://orcid.org/0000-0002-3191-6025

Natalia O. Ushko, https://orcid.org/0000-0002-6752-5560

Ievgen I. Fesenko, https://orcid.org/0000-0002-8901-1632

Olexander O. Tymofieiev, https://orcid.org/0000-00032110-707X

Maria O. Yarifa, https://orcid.org/0000-0003-3737-4658

Olha S. Cherniak, https://orcid.org/0000-0002-6372-0043

\section{Authors' Contributions}

I.I.F. and O.S.C. participated in data collection and wrote the manuscript. O.O.T. (Olexander O. Tymofieiev), M.O.Y., and N.O.U. participated in the study design and performed the analysis of the references. O.O.T. (Oleksii O. Tymofieiev) participated in the study design and coordination and helped to draft the manuscript. All authors read and approved the final manuscript.

\section{Consent for Publishing Photographs}

Written informed consent was obtained from the patients for publication of this article and accompanying images.

\section{Conflict of Interest}

No potential conflict of interest relevant to this article was reported.

\section{References}

1. Elghblawi E. Intense retroauricular lymphadenopathy postmicroneedling. J Cosmet Dermatol 2019;18:2048-9. https://doi. org/10.1111/jocd.12947

2. Ogassavara B, Tucunduva Neto RR, de Souza RR, Tucunduva MJ. Ultrasound evaluation of the morphometric patterns of lymph nodes of the head and neck in young and middle-aged individuals. Radiol Bras 2016;49:225-8. https://doi.org/10.1590/01003984.2015.0002

3. Bou-Assaly W. The forgotten lymph nodes: review of the superficial head and neck lymphatic system. J Radiol Imaging 2016;1:913. https://doi.org/10.14312/2399-8172.2016-3

4. Lengelé B, Hamoir M, Scalliet P, Grégoire V. Anatomical bases for the radiological delineation of lymph node areas. Major collecting trunks, head and neck. Radiother Oncol 2007;85:146-55. https:// doi.org/10.1016/j.radonc.2007.02.009

5. Eidlitz-Markus T, Zeharia A. Images in clinical medicine. Cat scratch disease lymphadenopathy. N Engl J Med 2006;354:e17. https://doi.org/10.1056/NEJMicm050180

6. Hung T, Huchzermeyer P. When a mastoid swelling is not mastoiditis. J Laryngol Otol 2000;114:376-7. https://doi. org/10.1258/0022215001905616

7. Marshall LR, Salib RJ, Mitchell TE, Moore I. A case of cranial fasciitis masquerading as acute mastoiditis. J Laryngol Otol 2009; 123:245-7. https://doi.org/10.1017/S0022215108002946

8. Lasisi O, Ogunleye A, Akang E. Squamous cell carcinoma of the mastoid - a report of two cases. Ghana Med J 2005;39:28-32. https://doi.org/10.4314/gmj.v39i1.35978

9. Sharma A, Kim JW, Paeng JY. Clinical analysis of neck node metastasis in oral cavity cancer. J Korean Assoc Oral Maxillofac Surg 2018;44:282-8. https://doi.org/10.5125/jkaoms.2018.44.6.282

10. Byun SS, Jung HD, Choi YD, Kim HS, Cha IH, Kim HJ. A case report of Kimura's disease in the parotid region. J Korean Assoc Oral Maxillofac Surg 2007;33:554-8.

11. Restrepo R, Oneto J, Lopez K, Kukreja K. Head and neck lymph nodes in children: the spectrum from normal to abnormal. Pediatr 
Radiol 2009;39:836-46. https://doi.org/10.1007/s00247-009-12505

12. Ludwig BJ, Wang J, Nadgir RN, Saito N, Castro-Aragon I, Sakai O. Imaging of cervical lymphadenopathy in children and young adults. AJR Am J Roentgenol 2012;199:1105-13. https://doi.org/10.2214/ AJR.12.8629

13. Ahuja AT, Evans RM. Practical head and neck ultrasound. Cambridge: Cambridge University Press; 2000.

14. Ying M, Ahuja A, Brook F, Brown B, Metreweli C. Sonographic appearance and distribution of normal cervical lymph nodes in a Chinese population. J Ultrasound Med 1996;15:431-6. https://doi. org/10.7863/jum.1996.15.6.431

15. Ahuja AT, Ying M, Ho SY, Antonio G, Lee YP, King AD, et al. Ultrasound of malignant cervical lymph nodes. Cancer Imaging 2008; 8:48-56. https://doi.org/10.1102/1470-7330.2008.0006

16. Ying M, Ahuja A. Sonography of neck lymph nodes. Part I: normal lymph nodes. Clin Radiol 2003;58:351-8. https://doi.org/10.1016/ s0009-9260(02)00584-6

17. Ahuja AT, Ying M. Sonographic evaluation of cervical lymph nodes. AJR Am J Roentgenol 2005;184:1691-9. https://doi. org/10.2214/ajr.184.5.01841691

18. Hernandez M, Chowdhury R, Woods J, Cabrera J, Hardigan PC. Management of suppurative cervical lymphadenitis in a healthy 24-year-old man. J Am Osteopath Assoc 2011;111:49-51.

19. McMillan JA, Feigin RD, DeAngelis CD, Jones MD Jr. Oski's pediatrics: principles and practice. 4th ed. New York (NY): Lippincott Williams \& Wilkins; 2006.

20. Tymofieiev OO. [Manual of maxillofacial and oral surgery]. 5th ed. Kyiv: Chervona Ruta-Turs; 2012. Russian.

21. Dudkiewicz M, Livni G, Kornreich L, Nageris B, Ulanovski D,
Raveh E. Acute mastoiditis and osteomyelitis of the temporal bone. Int J Pediatr Otorhinolaryngol 2005;69:1399-405. https://doi. org/10.1016/j.ijporl.2005.03.036

22. Scrafton DK, Qureishi A, Nogueira C, Mortimore S. Luc's abscess as an unlucky complication of mastoiditis. Ann R Coll Surg Engl 2014;96:e28-30. https://doi.org/10.1308/00358841 4X13946184901281

23. Nasir F, Asha'ari ZA. Bezold's abscess: a rare complication of acute otitis media. Malays Fam Physician 2017;12:26-8.

24. Gaffney RJ, O'Dwyer TP, Maguire AJ. Bezold's abscess. J Laryngol Otol 1991;105:765-6. https://doi.org/10.1017/s0022215100117256

25. Pattanayak S, Chatterjee S, Ravikumar R, Nijhawan VS, Vivek Sharma, Debnath J. Ultrasound evaluation of cervical lymphadenopathy: can it reduce the need of histopathology/cytopathology? Med J Armed Forces India 2018;74:227-34. https://doi. org/10.1016/j.mjafi.2017.04.005

26. Vazquez E, Castellote A, Piqueras J, Mauleon S, Creixell S, Pumarola $\mathrm{F}$, et al. Imaging of complications of acute mastoiditis in children. Radiographics 2003;23:359-72. https://doi.org/10.1148/ rg.232025076

How to cite this article: Tymofieiev OO, Ushko NO, Fesenko II, Tymofieiev OO, Yarifa MO, Cherniak OS. Suppurative mastoid lymphadenitis mimicking mastoiditis: a case report. J Korean Assoc Oral Maxillofac Surg 2021;47:398-402. https://doi. org/10.5125/jkaoms.2021.47.5.398 